\title{
Review
}

\section{Recent Advances in the Studies of Bread Baking Process and Their Impacts on the Bread Baking Technology}

\author{
Nantawan THERDTHAI ${ }^{1}$ and Weibiao ZHOU ${ }^{1,2 *}$ \\ ${ }^{1}$ Centre for Advanced Food Research, University of Western Sydney, Hawkesbury Campus, Penrith South DC NSW 1797, Australia \\ ${ }^{2}$ Food Science and Technology Programme, Department of Chemistry, National University of Singapore, 3 Science Drive 3, 117543 Singapore
}

Received April 30, 2003; Accepted July 3, 2003

\begin{abstract}
In bread-making, baking process is one of the key steps to produce the final product qualities including texture, color and flavor, as a result of several thermal reactions such as nonenzymatic browning reaction, starch gelatinization, protein denaturalization and so on. These thermal reactions are dominated by heat and mass transfer mechanisms inside an oven chamber as well as inside the dough pieces. Mathematical models have been developed to account for the heat and mass transfer phenomena and their consequent impacts on the product qualities. These studies have made the complicated baking process more clearly understood and predictable. As a result, baking process conditions can be optimized. In addition, new baking techniques and oven designs have been proposed in order to improve product qualities with better process economics.
\end{abstract}

Keywords: bread, baking, bakery, heat and mass transfer, temperature profile, heat flux, modeling

\section{Introduction}

The qualities of bakery products rely on both formula and processing conditions. Some qualities can be improved by optimizing a formula (Larsen \& Greenwood, 1991; Stampfli \& Nersten, 1995; Cauvain, 1998; Shimizu et al., 2003). However, without the optimum processing condition, the final product quality can be much degraded. Processing of bakery products mainly consists of mixing, proving, baking and cooling. Each of these processes dominates different quality attributes (Kilborn \& Preston, 1981; Larsen \& Greenwood, 1991; Wesley et al., 1998; Anonymous, 1995, 1998; Grenier et al., 2002). All quality attributes due to the thermal reactions are dominated by the baking process. The baking process is a step in which the raw dough piece is transformed into crumb and crust texture, under the influence of heat. The most apparent changes during this period are volume expansion, crust formation, inactivation of yeast and enzymatic activities, protein coagulation, partial starch gelatinization (Pyler, 1988) and moisture loss (Eliasson \& Larsson, 1993). With the requisite quality attributes, the production presumes a carefully controlled baking process. Key baking conditions which place vital influences on the final product quality include the rate and amount of heat application, the humidity level in a baking chamber and the baking time. In order to obtain the desired product qualities by baking, it is critical to fully understand these changes brought by the baking conditions and their interactions. Consequently, there have been many studies focussed on one or more of these issues. This article aims to review the recent studies and progresses on the heat and mass transfer phenomena during baking, quality changes in accordance with the baking conditions, baking process optimization and oven design.

\footnotetext{
*To whom correspondence should be addressed.
}

E-mail: chmzwb@nus.edu.sg

\section{Heat and mass transfer mechanisms during baking}

During baking, heat is transferred through the combination of all the three well-known mechanisms: conduction, convection and radiation. However, the actual form of combination and proportions are very different for heat transfer within dough pieces and heat transfer within an oven chamber.

\subsection{Heat transfer within dough}

Heat transfer in a dough is the combination of a conduction from band or tins to the dough, a conduction in the continuous liquid/solid phase of the dough and an evaporation-condensation in the gas phase of the dough. De Vries et al. (1989) stated 4 steps involved in the heat transport. Firstly, water evaporates at the warmer side of a gas cell that absorbs latent heat of vaporization. Then water vapor immigrates though the gas phase. When it meets the cooler side of the gas cell, it condenses and becomes water. Finally heat and water are transported by conduction and diffusion through the gluten gel to the warmer side of the next cell. The water diffusion mechanism becomes more important when dough tends to be a poor conductor that limits the heat transfer via conduction.

Zanoni et al. (1993) proposed a mechanistic model to describe the heat and mass transfer phenomena causing a series of physical, chemical and structural transformations in bread. Temperature, moisture, crust thickness, and increased volume were determined. Initially, convective evaporation of water occurs at the bread surface exposed to air and the crumb temperature increases linearly with time towards a constant value of $100^{\circ} \mathrm{C}$. Massive unbound water evaporates at this temperature with water boiling phenomenon. Therefore, this study assumed that the constant temperature of $100^{\circ} \mathrm{C}$ was the evaporation-front temperature. In the crust, a bread portion above the evaporation front, bound water evaporates. As a result, the crust temperature increases and tends to the oven temperature. The crust becomes thicker when 
the evaporation-front progressively advances towards the inside. For microwave heating of dough, Tong and Lund (1993) presented a 1-dimensional mathematical model of heat diffusion in Cartesian co-ordinates with internal heat generation. The model was developed based on a principal model involving water transfer in vapor phase, water content in the hygroscopic range and equilibrium moisture content at the product surface during baking. The considered parameters included water diffusivity, bulk density, thermal conductivity, latent heat, dielectric constant, and constant surface heat transfer coefficient. With similar parameters, Zanoni et al. (1994) developed a 2-dimensional axi-symmetric heat diffusion model. The phenomena were described separately for the upper and lower parts (crust and crumb). The upper part (crust) temperature was determined by equations including heat supply by convection, conductive heat transfer toward the inside, and convective mass transfer toward the outside. The lower part (crumb) temperature was determined by the Fourier's law. In addition to the Cartesian co-ordinates models, a 1-dimensional cylindrical co-ordinate model was also established by De Vries et al. (1989).

\subsection{Heat transfer within oven chambers}

In an oven chamber, molecules of air, water vapor, or combustion gases circulate throughout the oven and transfer heat by convection until they contact solid surfaces such as tin, band, conveyor and so on. Then heat transfer mode is changed to conduction. Radiant heat, which comes from the burner flames and all hot metal parts in the oven and travels in a straight line, has 2 characteristics different from the other modes of heat transfer. Firstly, it is subject to shadowing or blocking by intervening layers that are opaque to the radiation. Secondly, it is responsive to changes in the absorptive capacity of the dough. For example, color changes influence the progression of baking by increasing the absorption of infrared rays. An increase in the absorptive capacity for infrared rays, though not apparent visually, is an almost invariable concomitant of the visible change. As a result, there is a tendency for color changes to accelerate after the first browning appears. Such a tendency might be either good or bad depending on the desired characteristics in the final products. Therefore radiation tends to cause localized temperature differentials of an exposed surface, particularly the darkened area, whereas convection tends to even out temperature gradients (Matz, 1989).

Gupta (2001) developed a model to estimate the fraction of heat transfer modes to Indian flat bread in a continuous baking oven. It was found that conduction was the most important heat transfer mode from the oven chamber to the product. However, the model considered neither the direction of heat and flow to the product, nor the dynamic change of oven load during continuous baking. To deal with the complexity of heat distribution, product geometry and oven configuration, computational fluid dynamics (CFD) modeling technique has been used to study heat and mass transfer in an oven chamber (Fuhrmann et al., 1984; Carvalho \& Mertins, 1991; Velthuis et al., 1993; De Vries et al., 1995; Noel et al., 1998; Verboven et al., 2003; Therdthai et al., 2003). CFD is a numerical technique for solving partial differential equations. The main characteristic of this technique is the immediate discretization of the equation of flow into the physically threedimensional space. The solution domain is divided into a number of cells known as control volume. This process is called grid gen- eration. For computation, the scalar values such as pressure, dissipation, and kinetic energy of turbulence are determined at the volume center whereas the three components of vector variables such as velocity are determined on the volume faces (Mathioulakis et al., 1998).

The CFD models clearly show that increasing airflow velocity in the oven chamber would increase heat flux to the product (Carvalho \& Mertins, 1991; Velthuis et al., 1993; De Vries et al., 1995; Noel et al., 1998). In addition, a change in the chamber gas composition during baking also affects the heat flux. When the oven chamber was filled with radiation absorbing gases (water vapor and carbon dioxide), the average temperature was estimated to be increased by $5^{\circ} \mathrm{C}$ (Velthuis et al., 1993). So far, the effect of the migration of water and water vapor has not been integrated into the account of the heat transfer in an oven chamber yet.

\subsection{Mass transfer during baking}

Diffusion together with evaporation and condensation have been assumed to be the mass transfer mechanisms inside dough (Tong \& Lund, 1993; Zanoni et al., 1993; Zanoni et al., 1994; Thorvaldsson \& Janestad, 1999). The transport of water is driven by the gradients in water content. Thorvaldsson and Skjoldebrand (1998) found that at the center of a loaf, the measured water content decreased until the center temperature was at $70 \pm$ $5^{\circ} \mathrm{C}$ because of the volume expansion. However the total water content of the loaf should be constant because dough had not got a continuous pore system. When the temperature reached $70^{\circ} \mathrm{C}$, some structural changes commenced; as a result, the discrete pore became continuous and then allowed water to move freely.

To reduce the partial water vapor pressure due to the temperature gradient, water moves towards the loaf center and the surface by evaporation and condensation. As a result, crumb temperature increasing is accelerated. At the surface exposed to oven air where the partial water vapor pressure is far from saturation, the water vapor diffuses into the air; as a result, the surface starts to dry out (Eliasson \& Larsson, 1993). At this stage, a differentiation in bread structure is observed. Crumb is a wet core that contains as much moisture as the dough. Crust is a dried portion, the longer the baking is, the higher the thickness (Zanoni et al., 1994). In a study by Larsen and Greenwood (1991), the moisture content in the center of crumb was measured at $45.7 \%$, whereas the edge was at $37.2 \%$. This moisture differential has a consequence on staling mechanisms. It may affect the activity of some heat stable anti-staling amylolytic enzymes, because amylolytic activity increases with an increased hydration in dough. The moisture movement in crumb and crust can be described by the Fick's law (Sablani et al., 1998; Thorvaldsson \& Janestad, 1999).

Sablani et al. (1998) described a general equation for the temperature and moisture distribution within bakery products, which unfortunately contains a few errors. A corrected model for the combined heat and mass transfer in dough during baking can be presented as follows.

$$
\begin{gathered}
\rho_{b} c_{p_{b}} \frac{\partial T}{\partial t}=\nabla\left(k_{p} \nabla T\right)+\rho_{b} \lambda_{v} \frac{\partial C}{\partial t}, \\
\frac{\partial C}{\partial t}=\nabla(D \nabla C),
\end{gathered}
$$

with the boundary conditions:

$$
\begin{gathered}
k_{p} \nabla T \cdot \vec{n}=h_{t}\left(T_{a}-T_{s}\right)+\varepsilon \sigma\left(T_{w}^{4}-T_{s}^{4}\right), \\
D \nabla C \cdot \vec{n}=h_{m}\left(C_{a}-C_{s}\right),
\end{gathered}
$$


$t$ is time, $k_{p}$ is thermal conductivity, $\lambda_{v}$ is latent heat, $D$ is water diffusivity, $h_{t}$ is convective heat transfer coefficient, $h_{m}$ is convective mass transfer coefficient, $C$ is absolute moisture content, $\varepsilon$ is emissivity and $\sigma$ is Stefan-Boltzmann constant. The subscript $a$ stands for air, $s$ stands for surface, and $w$ stands for walls.

Thorvaldsson and Janestad (1999) further divided moisture $C$ into liquid water and water vapor, which diffused separately and simultaneously inside dough. A saturation equilibrium was assumed between the liquid water and water vapor.

\section{Physical changes during baking}

\subsection{Structural changes}

There are 2 major structural phenomena in a baking process. The first one is the transformation of a semi-fluid dough to a predominantly solid baked product. This transformation is characterized by the corresponding rheological properties. Changes in the rheological properties are affected by the baking conditions. The second structural phenomenon is the expansion of dough in the oven until its structure is fixed. The expansion is accompanied by a flow of material between the gas cells in the dough. Therefore, the resistance of the material to flow affects the oven rise or dough expansion.

\section{1) Solidification}

A metamorphosis from dough to bread involves crucial steps induced by starch gelatinization and transition from gel to coagel. The most striking changes are the opening of foam type of gas cells to produce pores and the solidification of aqueous bulk medium. The solidification is caused partly by gelatinization and partly by the loss of cohesiveness during transition from gluten gel to coagel. The bread is ready when the entire crumb reaches $100^{\circ} \mathrm{C}$ (Eliasson \& Larsson, 1993).

Starch gelatinization Starch granule is composed of amylose and amylopectin which forms crystalline together. The space between molecules is called amorphous. In the presence of water, when molecules are heated up to the point that water has enough energy to break the bond in the amorphous area, gelatinization starts (Medcalf, 1968). According to the nuclear magnetic resonance (NMR) baking (Engelsen et al., 2001), gelatinization starts at $55^{\circ} \mathrm{C}$ and finishes at $85^{\circ} \mathrm{C}$ when evaporation at the surface dominates. A series of processes at molecular scale include swelling, melting, disruption of starch granules and exudation of amylose (Bloksma, 1986). As a result of starch gelatinization, the partially swollen granules can be stretched into elongated forms to allow gas cells to expand. Therefore texture and structure of the product is dependent on starch gelatinization (Medcalf, 1968). The extent of starch gelatinization can be used as a baking index. To characterize the extent of starch gelatinization, Zanoni et al. (1995a) used a calorimeter to measure the quantity of heat uptake which related to the progression of starch gelatinization. Starch gelatinization reaction was found to follow the first-order kinetics as:

$$
(1-\alpha)=\exp (-k t)
$$

where $\alpha$ is the degree of gelatinization and $t$ is time. The reaction rate constant $k$ was dependent on temperature according to the Arrhenious equation with $k_{0}=2.8 \times 10^{19} \mathrm{~s}^{-1}$ and $E_{a}=139 \mathrm{~J} / \mathrm{mol}$.

Zanoni et al. (1995b) established the first model that combined the chemical-physical transformation model (i.e. starch gelatinization) with physical heat and mass transfer model. The model was useful to predict baking index with respect to differ- ent baking conditions. Besides the baking condition, addition of some ingredients would also influence the starch gelatinization. Emulsifiers, for example, delay the gelatinization, as a result, the period of time for volume expansion is prolonged or the increasing in viscosity is delayed. Therefore, adding emulsifiers is expected to improve the baking performance (Eliasson \& Larsson, 1993).

Protein denaturalization In wheat flour based products (bread, cracker, cookies, cake, etc.), dough is prepared through the formation of wheat gluten network. When dough is subject to high temperature during baking, changes in its viscoelastic properties are found, depending on the physico-chemical characteristics of the wheat gluten (Hansen et al., 1975). Heating at temperatures above $60^{\circ} \mathrm{C}$ leads to an increase in the storage modulus that characterizes elastic properties. This effect can be explained by the polymerization of glutenins as a result of thiol-disulphide interchange reaction. Thermal effect induces the change from gluten gel to coagel (Bloksma, 1986). Cuq et al. (2000) hypothesized that, changes in the solubility of wheat gluten during baking were dependent on its gliadin fraction. Otherwise the changes might depend on the level of high temperature which allowed the activation of thermosetting reactions producing intraand inter-molecular covalent bonds of protein network. In addition, Gerrard et al. (2003) found that additional crosslinks to a gluten network via Maillard reactions possibly produced better crumb texture and strength.

The change in gluten phase also enhances the effect of starch gelatinization, such as the transformation from a viscous dough into an elastic material (Bloksma, 1986). After the protein is denatured during baking, water adsorbed in the gluten is released. Then starch uses this water for gelatinization (Medcalf, 1968; Marston \& Wannan, 1976). Consequently, dough becomes a semi-rigid bread. Before baking, water in the dough is estimated to be combined with starch (46\%), protein (31\%) and pentosan $(23 \%)$. After baking, water is only associated with starch and pentosan (Bushuk, 1966).

\section{2) Expansion}

Carbon dioxide gas is mainly produced by yeast and partially produced by some baking powder. The production of carbon dioxide gas by yeast continues at an increased rate during the first stage of baking until yeast is destroyed at a temperature of about $55^{\circ} \mathrm{C}$. According to the Gay-Lussac law, occluded gas expands when temperature increases from $25^{\circ} \mathrm{C}$ to $70^{\circ} \mathrm{C}$ (Bloksma, 1986). At temperatures below $55^{\circ} \mathrm{C}$, volume expansion is slightly influenced by temperature. However temperature shows significant effect on volume expansion, after dough temperature reaches $60^{\circ} \mathrm{C}$ (Fan et al., 1999). When temperature increases during baking, the solubility of carbon dioxide in a liquid dough phase decreases. Then dissolved carbon dioxide vaporizes. At the same time, saturated vapor pressure of water increases rapidly; as a result, gas cells expand. In the presence of a constant pressure, the volume of the occluded gas increases by a factor of 1.15 (Bloksma, 1986). However the pressure remains constant until dough temperature reaches $50^{\circ} \mathrm{C}$ because dough viscosity does not affect oven rise up to this temperature. After that the increased viscous resistance causes an increase in pressure (Fan et $a l .$, 1999). If the pressure increases, the expansion will be accordingly decreased. The expansion is ceased by the exhaustion of baking powder, by the inactivation of yeast at higher temperature 
and by the resistance of the dough to extension. The resistance can be due to either the viscous resistance of the bulk to deformation or a crust formation at the surface (Bloksma, 1986). To predict the volume expansion in accordance with the thermallyinduced release of carbon dioxide gas and water vapor from aqueous dough phase, Fan et al. (1999) established the following mathematical model:

$$
V=\frac{4}{3} \pi R^{3} N \rho+1,
$$

where $V$ is relative volume, $R$ is gas bubble radius (m), $N$ is number of gas cells in the dough $\left(\mathrm{kg}^{-1}\right)$ and $\rho$ is density of gass-free dough $\left(\mathrm{kg} / \mathrm{m}^{3}\right)$. The model showed a good agreement with the published data from literature, although the effect of elasticity was ignored.

The volume expansion can be monitored by using a portable video camera through an oven window. Analysis of the images allowed an evaluation of the sample height with an accuracy of $\pm 1 \mathrm{~mm}$ (Zanoni et al., 1993). An apparatus from Hunterlab measures the product height and color at the same time. It was already applied to biscuit baking (McFarlane, 1995a). Kim and Cho (1997) applied a monotone image processing system using an edge detection technique. The height of a bread was measured for calculating the bread volume.

The combination of changing in rheological properties and gas production and evaporation results in loss of gas retention. The original structure is transformed into a sponge-like structure in which gas cells are interconnected (Bloksma, 1986). The transformed structure is composed of crumb and crust. Crumb has a pore structure which is complexly formed during oven spring. The pore surface consisting of a mono-molecular lipid firms with a few patches of polymerized high molecular weight storage protein units dispersed in it. Crust is a hard, vitreous surface layer formed of collapsed crumb pore walls. It is a result of dried starch gel with dispersed protein and lipid aggregates (Eliasson \& Larsson, 1993). Crust thickness could be measured by following the inwards movement of the $100^{\circ} \mathrm{C}$ isotherm front in the product (Wahlby \& Skjoldebrand, 2002).

\subsection{Color and flavor development}

1) Color is the important characteristic of baked products, contributing to consumer preference. In bread crust, the higher temperature and lower water content activate nonenzymatic browning reactions including Maillard reactions (sugar-amine) and caramelization (Gogus et al., 2000). At the beginning of a Maillard reaction, furosine amino acid is formed. However, the furosine decreases after a high intensity is reached. In contrast, hydroxymethylfurfural, an intermediate product in the Maillard reaction and sugar degradation, keeps increasing with higher temperature and baking time (Ramirez-Jimenez et al., 2000). The resulted brown polymeric compound is called melanoidine. The browning reaction rate depends on water activity and temperature. The water activity that produces the maximum browning reaction rate is in the range of 0.4 and 0.6 depending on the type of food substance (Gogus et al., 2000). At temperatures below $60^{\circ} \mathrm{C}$, the browning reaction performs as a zero-order reaction. When temperature is higher, reaction curve follows a first-order reaction. Due to the short period of sub- $60^{\circ} \mathrm{C}$ surface temperature in baking processes, the overall color reaction is assumed to follow the first-order kinetics (Zanoni et al.,1995c; Moyano et al., 2002). Its kinetic constant increases with an increased temperature (Ibarz et al., 2000) and a decreased moisture content (Moyano et al., 2002), following Arrhenius equation. In bread baking, crust browning reaction occurs at temperatures greater than $110^{\circ} \mathrm{C}$ (Wahlby \& Skjoldebrand, 2002).

Considering reaction kinetics, Zanoni et al. (1995c) developed the following mathematical model to quantify the browning of bread crust during baking.

$$
\Delta E_{\infty}-\Delta E=\Delta E_{\infty} \exp (-k t)
$$

where $\Delta E$ is the color difference tending asymptotically to $\Delta E_{\infty}=52$ which corresponded to the burnt samples and $t$ is baking time. The reaction rate constant $k$ was dependent on temperature according to the Arrhenius equation with $k_{0}=42,000 \mathrm{~s}^{-1}$ and $E_{a}=64,151 \mathrm{~J} / \mathrm{mol}$.

Color can be measured by Infrared Engineering (Colorex) sensor or Hunterlab. The color is presented in L-a-b system. A light (D65) is generated to present under filters in front of a product surface. The resulted light is detected and transformed into an electrical signal with $2 \%$ uncertainty in the case of Colorex (Trystram, 1997). Kim and Cho (1997) used a monochrome image to identify crust browning. However, they suggested to use a color image to enhance the identification. Moreover, a Food Analyzer can take a black and white photo of the crust surface. Its software can then calculate the amount of reflected light from the surface (Wahlby \& Skjoldebrand, 2002). However, RamirezJimenez et al. (2000) claimed that color intensity measurement was less sensible than measuring the intermediate compound, hydroxymethylfurfural. Therefore they suggested hydroxymethylfurfural to be used as a browning indicator for sliced bread toasting.

2) Flavor is another quality attribute developed during baking process in the form of $n$-heterocycles via Maillard reactions. 2-Acetyl-1-pyroline and 2-acetyltetrahydro pyridine are the major flavor compounds formed in wheat flour bread crust. Based on the relationship between flavor development and progress of baking, a flavor sensor was developed to be used as a process indicator for baking and toasting processes (Kohl et al., 2001).

During baking, the flavor compounds formed are adsorbed by pore curvatures. Crust structure also provides a barrier against the loss of flavors (Eliasson \& Larsson, 1993).

\subsection{Moisture loss}

Almost all moisture loss in bakery products takes place during the baking process because of evaporation. Variations in moisture loss are caused by dough nature and baking condition (Swortfiguer, 1968). As stated earlier, due to the effect of heat during baking, dough structure is changed to a continuous pore structure to allow water to move. Some water vapor loses through crust layer by evaporation while some water vapor condenses at dough center. Consequently, moisture content and water activity change and moisture gradients are formed (Czuchajowska et al., 1989). According to a model based on water evaporation and diffusion, Hall et al. (1998) found that after baking, the water content of crumb remained the same as the initial dough water content at $45 \%$ whereas the crust water content was close to zero. Therefore the total moisture loss was basically from the loss at the surface. Thorvaldsson and Skjoldebrand (1998) found that a total moisture loss of $53 \mathrm{~g}$ per loaf could be from the top crust $(29 \mathrm{~g})$, the layer below the top crust (12 g) and the side crust (12 g). In the case of a frozen bun, Wahlby and Skjoldebrand (2002) found that during re-heating, the moisture loss from bread buns without 
crust was 3 times greater than the moisture loss from bread buns with crust. This was because the crust acted as a barrier to mass transfer. Heat supplied to the surface was used for heating the surface and then conducted through the crust. Without a crust, heat supplied to the surface was used for evaporating the water from buns. As a result, the center temperature of buns without crust leveled off at a lower level than that of buns with crust.

Moisture loss can be measured from the reduced loaf weight using a load cell (McFarlane, 1995b). In addition, a non-contact method based on near infrared (NIR) absorption can be applied. NIR wavelength is absorbed at the product surface in proportion to the number of $\mathrm{OH}$ bonds encountered. However, this method cannot measure the moisture gradient inside a product. To measure moisture content and density at the same time, microwave could be used. Microwave measures moisture content through the interaction of an electromagnetic field with the dielectric and power dissipative properties of water (Trystram, 1997).

\section{Effect of baking parameters on product quality 4.1. Temperature}

As stated previously, temperature dominates product quality during baking, because it affects enzymatic reaction, volume expansion, gelatinization, protein denaturalization, nonenzymatic browning reaction and water migration (Anonymous, 2002). Temperature gradient provides a pressure gradient in the product. Then the pressure gradient causes the lattice to dilate in one dimension, from the centre of bread toward the surface. If such an expanded foam lattice is transformed to be a pore system, the pore structure will show the same dilatation. As a result, such bread is easily fractured along the inside of the crust. Therefore, to avoid the dilatation effect, the heat gradient in an oven has to be adapted to the strength of the gluten film forming the interface of the gas cells (Eliasson \& Larsson, 1993). Not only how much temperature is required, but when it should be applied is also important. The optimum level of temperature is needed to be supplied at a right time. Otherwise, product quality can be degraded. For example, supplying too high temperature at the early stage of baking might cause an early crust formation, shrunk bread loaf and too dark crust (Therdthai et al., 2002). Use of too high temperature at the bottom may cause holes towards the bottom of a loaf, and then triangular shape. Moreover, cavity at the bottom is possibly found (Cauvain \& Young, 2001).

\subsection{Airflow velocity}

In addition to temperature, airflow velocity affects baking quality. Lack of product uniformity is possibly due to the nonuniformity of airflow around product during baking. It was confirmed that heat flux to the product could be increased by increasing airflow velocity (Velthuis et al., 1993; Carvalho \& Nogueira, 1997). According to Sato et al. (1987), increasing airflow velocity results in a higher weight loss, lower softness and darker surface. Therefore either baking time or baking temperature should be reduced with respect to an increase in heat transfer rate. However, baking process requires a minimum temperature to produce an adequate color. When bread is baked under very low temperature, very high air flow velocity is required to increase the drying rate at surface. Nonetheless only drying rate is not enough to produce an acceptable crust color (Wahlby, 1998). Similarly, in the case of a microwave baking oven, product is baked at low environment temperature and short time. Not only the lack of baking color and flavor, but condensation at the product surface is also a major problem of the microwave baked products (Sumnu, 2001). To overcome the problem, in one study, airflow velocity was increased. As a result, heat and mass transfer coefficients were increased. However, the mass transfer coefficient was still not high enough to rapidly remove the significant moisture accumulation. Therefore higher forced airflow velocity should be applied at the optimal area to increase the surface transfer coefficients (Verboven et al., 2003). When mass transfer coefficient was high enough to significantly reduce the water content on the surface, color and flavor development could be enhanced at the same time as texture improvement.

\subsection{Baking time}

Kinetic reactions including starch gelatization and browning reaction depend on not only temperature, but also baking time. Therefore, to reduce the baking time by increasing either airflow velocity or baking temperature, it has to be ensured that gelatinization and browning reaction are completed, otherwise product quality can be degraded (Therdthai et al., 2002). Even though the starch gelatization and browning reaction are completed, quality of the product baked by short and long baking times can still be quite different. Longer baking time can produce loaf side caving as well as less softness (Cauvain \& Young, 2001). The combination of baking temperature and baking time should be optimised to produce a desired product (Therdthai et al., 2002).

\subsection{Humidity}

With the same oven temperature and air flow velocity, increasing air humidity by either injecting water vapor into the oven chamber or water vapor migration from the product increases heat flux. According to a CFD model, the average temperature of an oven composed of $100 \%$ water vapor can be $5^{\circ} \mathrm{C}$ higher than that of an oven containing only dry air (Velthuis et al., 1993). However water vapor could limit the crust formation (Chevallier et al., 2002). Therefore water vapor is normally applied to an oven only at the beginning of a baking process for bread products. On the other hand, an improper water vapor control and damper control could render the humidity being too low in an oven chamber. As a result, baking loss might increase (Swortfiguer, 1968).

\section{Baking condition profiles}

\subsection{Air temperature profile}

In a typical bread baking process, baking air temperature profile can be divided into 3 stages (Swortfiguer, 1968). The first stage starts at around $204^{\circ} \mathrm{C}$ and is composed of one-fourth of a total baking time of $26 \mathrm{~min}$. The temperature of outer crumb increases at an average rate of $4.7^{\circ} \mathrm{C}$ per min to $60^{\circ} \mathrm{C}$. An increase in temperature enhances enzymatic activity and yeast growth resulting in an oven rise (a perceptible increase in loaf volume). When temperature reaches $50-60^{\circ} \mathrm{C}$, most enzymes are inactivated and yeast is killed. Consequently, carbon dioxide is released from solution resulting in a rapid loaf expansion called oven spring. The volume increases by one-third of the original. Furthermore, surface skin loses elasticity, thickens and begins to appear browning color. In the second stage, oven air temperature is maintained at $238^{\circ} \mathrm{C}$ for $13 \mathrm{~min}$. Crumb temperature increases at a rate of $5.4^{\circ} \mathrm{C}$ per min to $98.4-98.9^{\circ} \mathrm{C}$ before keeping constant. At this temperature, all reactions are maximized, including evaporation, starch gelatinization, and protein coagulation. 
Dough becomes crumb structure from outer to inner portions by penetrating heat. A typical browning crust can be observed when crust temperature reaches $150-205^{\circ} \mathrm{C}$. Finally, the volatilization of organic substances is designated as the bake-out-loss. This period also takes one-fourth of the total baking time.

Schultz (2000) designed an on-line monitoring system for a travelling tray oven. The oven air temperature was monitored by thermocouples with thermal shielding to control the baking temperature at a set point. The thermocouples were connected to the controller. Temperature readings were acquired via serial lines using the MODBUS RTU protocol. The returned data included the measured air temperature, set-point, and the burner state.

\subsection{Tin surface temperature profile}

The correlation between air temperature and product quality is poor because there are some other parameters affecting the product quality at the same time. Therdthai et al. (2002) overcame the problem by using temperature at the product surface, which is a consequence of all baking parameters, as a key profile to relate with the product quality. In a hi-top bread, Thorvaldsson and Skjoldebrand (1998) noticed that temperature on the bottom surface was heated up slightly faster than the side surface. This was due to the heat conduction through the plate. At temperatures below $80^{\circ} \mathrm{C}$, the top temperature was about $0-10^{\circ} \mathrm{C}$ lower than the bottom temperature. Then it became higher than both the bottom and side temperatures which contacted the tin. For a square bread baked in a closed tin, the surface temperature profiles on top, bottom and side were different from those of the hi-top bread. The bottom temperature seemed to be slightly higher than the top temperature in the later stage of a baking process. Therdthai et al. (2002) developed mathematical models to predict the final crumb temperature, crust color and total weight loss using the tin surface temperatures. Based on the models, the optimized surface temperature profile was proposed to be at $115^{\circ} \mathrm{C}$, $130^{\circ} \mathrm{C}, 156^{\circ} \mathrm{C}$ and $176^{\circ} \mathrm{C}$ in zone1, zone2, zone 3 and zone 4 respectively, for a total baking time of $27.4 \mathrm{~min}$. Each zone occupied a quarter of the total baking time. Alternatively, temperature profiles for shorter baking times were also presented. All optimum surface temperature profiles aimed to minimize the weight loss during baking with a completed gelatinization and an acceptable crust color.

\subsection{Heat flux profile}

An alternative way to measure the combined influence of all baking parameters is the wall heat flux measurement. Heat flux is defined as the heat transfer rate per unit area that is required for baking from the oven chamber to the product (Van Son, 2001). Heat flux measurement was claimed to be the more useful method than air temperature measurement, for controlling the quality of bakery products (Fahloul et al., 1995; Carvalho \& Nogueira, 1997; Van Son, 2001). For bread, Carvalho and Nogueira (1997) showed the influence of airflow velocity in an oven chamber on heat flux to bread as well as the possibilities to optimize the heat flux on the top, bottom and side of the product to obtain a better heat distribution. In addition, radiation was confirmed to be the most important heat transfer mode for the baking process of a hitop bread, particularly in a natural convection oven. This coincides with the result from a CFD model developed by Velthuis et al. (1993). The fraction of heat transfer modes can be varied depending on the product nature and oven type. Gupta (2001) found that conduction heat transfer mode played the most impor- tant role for baking Indian unleavened flat bread (chapati) in a direct fired burner oven.

To measure the total heat flux, Fahloul et al. (1995) used a sensor made of copper joined to a steel heat sink by a copper bridge fitted with 2 thermocouples. The temperature readings from these 2 thermocouples together with temperatures of the heat sink and ambience were used to calculate the total heat flux. In 2001, the TNO Nutrition and Food Research Institute developed a heat flux sensor capable of measuring convective heat flux and radiative heat flux separately. The sensor was composed of 2 parts: a black sensor and a golden sensor. The black sensor was used for absorb the total heat flux whereas the golden sensor was used to reflect the radiative heat flux. By subtracting, the radiative heat flux can be calculated (Van Son, 2001). However, both of the sensors could not account for the conductive heat flux.

\section{Baking oven design}

An oven is basically composed of a baking chamber and a heating system. The baking chamber is normally designed as a rectangular box formed by steel lining sheet supported by a steel frame. Oven walls on top, sides and bottom are insulated. For the heating, there are several systems to generate heat and supply it to the oven, including fuel oil, natural gas, propane-butane, and electricity. Theoretically, fuel oil provides 140,000 BTU per gal, natural gas provides 37,000 BTU per $\mathrm{m}^{3}$, manufactured gas provides 20,350 BTU per $\mathrm{m}^{3}$ and electricity provides 3142 BTU per $\mathrm{kWh}$. Electricity is cleaner and easier for maintenance, but the cost is not economic. Generally, $1 \mathrm{~kg}$ of bread requires around 340-450 BTU to complete a baking. However, additional energy is required to heat the tins (around 90 BTU per $\mathrm{kg}$ of dough) and to compensate for losses through the walls (Matz, 1989).

Recently CFD has been applied to provide useful information to optimize various aspects of baking oven design to improve product quality (De Vries et al., 1995). The effect of airflow patterns in a domestic forced convection oven on heat distribution was established. Therefore the oven configuration can be modified to obtain a more uniform heat distribution (Noel et al., 1998). Oven can also be designed to provide an optimum heat flux from the combination of heat transfer modes to the top, bottom and side of a product (Carvalho \& Nogueira, 1997). Similarly, oven can be manipulated in order to achieve an optimum surface temperature profile. In addition to the quality issues, energy consumption and efficiency are also important. Fuhrmann et al. (1984) proposed a method to reduce the energy consumption by using a re-circulation system.

In addition to the conventional baking ovens as above mentioned, microwave ovens have been introduced into baking, due to their advantage of saving energy and time and improving nutritional quality. However microwave-baked products have yet to be fully accepted by the consumers. The difference in product quality is mainly because of the difference in the heat transfer modes between a conventional baking oven and a microwave oven. The microwave increases the product temperature rapidly by enhancing the movement of water molecules. Therefore ambient temperature in the microwave oven is low. As a result, the Maillard reactions at the dough surface might not be completed. In addition, a short baking time might cause an incomplete starch gelatinization and flavor development (Sumnu, 
2001). Therefore, Verboven et al. (2003) tried to modify a traditional microwave oven by combining it with natural and forced convection regimes. According to a CFD simulation, it was found that the mass transfer coefficient and the uniformity of heat transfer coefficient at the food surface could be significantly increased, when air inlets and outlets were placed optimally as well as different types of fan were applied.

\section{Trend of research on bread baking process}

As reviewed in the above, studies on heat and mass transfer within a dough/bread and the consequent changes in the product during baking therefore the final quality have been well developed and the various mechanisms clearly explained. However, information on how to manipulate the oven condition optimally to produce a quality bread is still lacking and poorly understood. This is because of the complicated interactions between the baking parameters and the specifications of each oven type and product type. CFD approach has been used to produce some required information and seems promising. Although a CFD model is specific to a particular oven structure, modifications can be made to fit it to other cases. Therefore it becomes more and more popular in the bread baking research. However most of the established CFD models have not dealt with the dynamic changes in a continuous baking process. We expect this to be one of the directions for future bread baking research.

Besides process understanding and optimization, well designed instruments for monitoring and controlling a process and product quality are also necessary. New development tends to monitor product quality directly on-line. Non-contact type of instruments and measurement is ideal for baking processes. New control system can be developed in such a way that the product quality can be controlled directly via the measured data, instead of indirectly via the modeled data through process parameters. This will overcome the problem caused by the model's inaccuracy.

With a better understanding of the dynamic changes in a continuous baking process and through on-line quality sensors, an on-line optimization for bread baking could be developed in the future to ensure that every loaf has the same color, same height, same moisture loss and same degree of flavor.

\section{Nomenclatures}

C absolute moisture content $(\mathrm{kg} / \mathrm{kg})$

$D$ mass diffusivity $\left(\mathrm{m}^{2} / \mathrm{s}\right)$

$\Delta E$ color difference (dimensionless)

$N$ number of gas cells in the dough $\left(\mathrm{kg}^{-1}\right)$

$R \quad$ gas bubble radius (m)

$T$ temperature $(\mathrm{K})$

$V$ relative volume (dimensionless)

$c_{p} \quad$ specific heat $(\mathrm{J} / \mathrm{kg} \cdot \mathrm{K})$

$h_{t} \quad$ convective heat transfer coefficient $\left(\mathrm{W} / \mathrm{m}^{2} \mathrm{~K}\right)$

$h_{m}$ convective mass transfer coefficient $(\mathrm{m} / \mathrm{s})$

$k$ reaction rate constant $\left(\mathrm{s}^{-1}\right)$

$k_{p}$ thermal conductivity $(\mathrm{W} / \mathrm{m} \cdot \mathrm{K})$

$t$ time (s)

$\alpha \quad$ degree of gelatinization (dimensionless)

$\sigma \quad$ Stefan-Boltzmann constant $\left(\mathrm{W} / \mathrm{m}^{2} \mathrm{~K}^{4}\right)$

$\varepsilon \quad$ emissivity (dimensionless)

$\rho$ density $\left(\mathrm{kg} / \mathrm{m}^{3}\right)$ $\lambda_{v}$ latent heat $(\mathrm{kJ} / \mathrm{kg})$

[Subscripts]

a air

$s \quad$ surface

\section{References}

Anonymous. (1995). Controlling your proof time. BRI Bakers' Technical Bulletin, No. 95/01.

Anonymous. (1998). The breadmaking process: the important of moulding. BRI Bakers' Technical Bulletin, No. 98/01.

Anonymous (2002). Heat flow. BRI Technical Bulletin. March 2002.

Bloksma, A.H. (1986). Rheological aspects of structural changes during baking. In "Chemistry and Physics of Baking," ed. by J.M. Blanshard, P.J.Frazier, and T. Galliard. The Royal Society of Chemistry, Great Britain, pp. 170-178.

Bushuk, W. (1966). Distribution of water in dough and bread. The Bakers Digest, 40, 38-40.

Carvalho, M.G and Mertins, N. (1991). Mathematical modeling of heat and mass transfer phenomena in baking ovens. In "Computational Methods and Experiment Measurements V," ed. by A. Sousa, C.A. Brebbia and G.M. Carlomagno. Computational Mechanics Publications, pp. 359-370.

Carvalho, M.G and Nogueira, M. (1997). Improvement of energy efficiency in glass-melting furnaces, cement kilns and baking ovens. Appl. Therm. Eng., 17, 921-933.

Cauvain, S. (1998). Bread-the product. In "Technology of Breadmaking," ed. by S.P. Cauvain and L. Young. Blackie Academic \& Professional, Great Britain, pp. 1-17.

Cauvain, S. and Young, L. (2001). "Baking Problems Solved." Woodhead Publishing Limited and CRC Press LLC, England.

Chevallier, S., Della, G., Colonna, P., Broyart, B. and Trystram, G. (2002). Structural and Chemical modifications of short dough during baking. J. Cereal Sci., 35, 1-10.

Cuq, B., Boutrot, F., Redl, A. and Lullien-Pellerin, V. (2000). Study of the temperature effect on the formation of wheat gluten network: influence on mechanical properties and protein solubility. J. Agric. Food Chem., 48, 2954-2959.

Czuchajowska, Z., Pomeranz, Y. and Jeffers, H.C. (1989). Water activity and moisture content of dough and bread. Cereal Chem., 66, $128-132$.

De Vries, U., Sluimer, P. and Bloksma, A.H. (1989). A quantitative model for heat transport in dough and crumb during baking. In "Cereal Science and Technology in Sweden," ed. by N.-G. Asp. STU Lund University, Lund, pp. 174-188.

De Vries, U., Velthuis, H. and Koster, K. (1995). Baking ovens and product quality-a computer model. Food Sci. Technol., 9, 232-234.

Engelsen, S.B., Jensen, M.K., Pedersen, H.T., Norgaard, L. and Munck, L. (2001). NMR baking and multivariate prediction of instrumental texture parameters in bread. J. Cereal Sci., 33, 59-69.

Eliasson, A.-C. and Larsson, K. (1993). Cereals in "Breadmaking: A Molecular Colloidal Approach.” Marcel Dekker Inc., USA.

Fahloul, D, Trystram, G., McFarlane, I. and Duquenoy, A. (1995). Measurement and predictive modeling of heat fluxes in continuous baking ovens. J. Food Eng., 26, 469-479.

Fan, T., Mitchell, J.R. and Blanshard, J.M.V. (1999). A model for the oven rise of dough during baking. J. Food Eng., 41, 69-77.

Fuhrmann, E., Sockel, H. and Steinruck, P. (1984). Improvement of continuous baking oven's efficiency. J. Wind Eng. Ind. Aerodynamics, 16, 201-212.

Gerrard, J.A., Brown, P.K. and Fayle, S.E. (2003). Maillard crosslinking of food proteins III: the effects of glutaraldehyde, formaldehyde and glyceraldehyde upon bread and croissants. Food Chem., 80, 4550.

Gogus, F., Duzdemir, C. and Eren, S. (2000). Effects of some hydrocolloids and water activity on nonenzymatic browning of concentrated orange juice. Nahrung, 44, 438-442.

Grenier, A., Monteau, J.Y., Bail, A.L. and Hayert, M. (2002). Effect of external conditions on the rate of post-baking chilling of bread. $J$. Food Eng., 55, 19-24.

Gupta, T.R. (2001). Individual heat transfer modes during contact bak- 
ing of Indian unleavened flat bread (chapati) in a continuous oven. J. Food Eng., 47, 313-319.

Hansen, L.P., Johnston, P.H. and Ferrel, R.E. (1975). Heat-moisture effects on wheat flour. I. Physical-chemical changes of flour proteins resulting from thermal processing. Cereal Chem., 52, 459-472.

Hall, J.E., Bravington, V. and Otto, S.R. (1998). Simulation of the transition from dough to bread. Proceedings of ACoFoP IV, Goteborg, Sweden, Sept. 21-23, 1998, pp. 503-509.

Ibarz, A., Pagan, J. and Garza, S. (2000). Kinetic models of non-enzymatic browning in apple puree. J. Sci. Food Agric., 80, 1162-1168.

Kilborn, R.H. and Preston, K.R. (1981). Device senses changes in dough consistency during dough mixing part1: with Tweedy mixer. Bakers J., April/May, 16-19.

Kim, S. and Cho, S.I. (1997). Neural network modeling and fuzzy control simulation for bread-baking process. Transac. ASAE, 40, 671-676.

Kohl, D., Heinert, L., Bock, J., Hofmann, Th. and Schieberle, P. (2001). Gas sensors for food aroma during baking and roasting processes based on selective odorant measurements by an array (HRGC/SOMMSA). Thin Solid Films, 391, 303-307.

Larsen, N.G. and Greenwood, D.R. (1991). Water addition and the physical properties of mechanical dough development doughs and breads. J. Cereal Sci., 13, 195-205.

Marston, P.E. and Wannan, T.L. (1976). Bread baking-the transformation from dough to bread. The Bakers Digest, 50, 24-49.

Mathioulakis, E., Karathanos, V.T. and Belessiotis, V.G. (1998). Simulation of air movement in a dryer by computational fluid dynamics: Application for the drying of fruits. J. Food Eng., 36, 183-200.

Matz, S. (1989). "Equipment for Bakers.” Elsevier Science Publishers, USA.

McFarlane, I. (1995a). Online combined color and height sensor for bakeries. ASAE-Food Processing Automation Conference IV. McCormick Place, Chicago, Illinois, pp. 34-39.

McFarlane, I. (1995b). "Automatic Control of Food Manufacturing Processes." Blackie Academic \& Professional, Great Britain.

Medcalf, D.G. (1968). Wheat starch properties and their effect on bread baking quality. The Bakers Digest, 42, 48-50.

Moyano, P.C., Rioseco, V.K. and Gonzalez, P.A. (2002). Kinetics of crust color changes during deep-fat frying of impregnated french fries. J. Food Eng., 54, 249-255.

Noel, J.Y., Ovenden, N.A. and Pochini, I. (1998). Prediction of flow and temperature distribution in a domestic forced convection electric oven. Proceedings of ACoFoP IV, Goteborg, Sweden, Sept. 2123, 1998, pp. 491-496.

Pyler, E.J. (1988). "Baking Science \& Technology, Volume II". Sosland Publishing Company, USA.

Ramirez-Jimenez, A., Guerra-Hernandez, E. and Garcia-Villanova, B. (2000). Browning indicators in bread. J. Agric. Food Chem., 48, 4176-4181.

Sablani, S.S., Marcotte, M., Baik, O.D. and Castaigne, F. (1998). Modelling of simultaneous heat and water transport in the baking process. Lebensm.-Wiss. u.-Technol., 31, 201-209.

Sato, H., Matsumura, T. and Shibukawa, S. (1987). Apparent heat transfer in a forced convection oven and properties of baked food. $J$. Food Sci., 52, 185-193.
Schultz, B. (2000). Mechatronic bakery. Master of Engineering Thesis, University of Southern Queensland, Australia.

Shimizu, Y., Maeda, T., Hidaki, Y., Tani, H. and Morita, N. (2003). Identification and effect of ethyl galactoside on the properties and baking quality of dough. Food Res. Int., 36, 373-379.

Stampfli, L. and Nersten, B. (1995). Review: emulsifiers in bread making. Food Chem., 52, 353-357.

Sumnu, G. (2001). A review on microwave baking of foods. Int. J. Food Sci. Technol., 36, 117-127.

Swortfiguer, M.J. (1968). Dough absorption and moisture retention in bread. The Bakers Digest, 42, 42-44, 67.

Tong, C.H. and Lund, D.B. (1993). Microwave heating of baked dough products with simultaneous heat and moisture transfer. $J$. Food Eng., 19, 319-339.

Therdthai, N., Zhou, W. and Adamczak, T. (2002). Optimization of the temperature profile in bread baking. J. Food Eng., 55, 41-48.

Therdthai, N., Zhou, W. and Adamczak, T. (2003). Two dimensional CFD modeling and simulation of an industrial continuous bread baking oven. J. Food Eng., 60, 211-217.

Thorvaldsson, K. and Janestad, H. (1999). A model for simultaneous heat, water and vapor diffusion. J. Food Eng., 40, 167-172.

Thorvaldsson, K. and Skjoldebrand, C. (1998). Water diffusion in bread during baking. Lebensm.-Wiss. u.-Technol., 31, 658-663.

Trystram, G. (1997). Computerized process control for the bakery/ cereal industry. In "Computerized Control Systems in the Food Industry,” ed. by G.S.Mittal. Marcel Dekker, Inc., USA, pp. 491-512.

Van Son, M. (2001). Flux future. Asia-Pacific Baker, August, 16-22.

Velthuis, H., Dalhuijsen, A. and De Vries, U. (1993). Baking ovens and product quality. Food Technol. Int. Eur., 61-66.

Verboven, P., Datta, A.K., Anh, N.T., Scheerlinck, N. and Nicolai, B.M. (2003). Computation of airflow effects on heat and mass transfer in a microwave oven. J. Food Eng., in press.

Wahlby, U. (1998). Food quality in a low temperature convection oven-experiments and modilisation during development of a new household oven. Proceedings of ACoFoP IV, Goteborg, Sweden, Sept. 21-23, 1998, pp. 479-484.

Wahlby, U. and Skjoldebrand, C. (2002). Reheating characteristics of crust formed on buns, and crust formation. J. Food Eng., 53, 177184.

Wesley, I.J., Larsent,N., Osborne, B.G. and Skerritt, H. (1998). Noninvasive monitoring of dough mixing by near infrared spectroscopy. J. Cereal Sci., 27, 61-69.

Zanoni, B., Peri, C. and Pierucci, S. (1993). A study of the bread-baking process I: a phenomenological model. J. Food Eng., 19, 389398.

Zanoni, B., Pierucci, S. and Peri, C. (1994). Study of bread baking process-II. Mathematical modelling. J. Food Eng., 23, 321-336.

Zanoni, B., Schiraldi, A. and Simonetta, R. (1995a). A naive model of starch gelatinization kinetics. J. Food Eng., 24, 25-33.

Zanoni, B., Peri, C. and Bruno, D. (1995b). Modeling of starch gelatinization kinetics of bread crumb during baking. Lebensm.-Wiss. u.Technol., 28, 314-318.

Zanoni, B., Peri, C. and Bruno, D. (1995c). Modeling of browning kinetics of bread crust during baking. Lebensm.-Wiss. u.-Technol., 28, 604-609. 